\title{
Engineering Design: Structure, Value and Assessment
}

\author{
Ian Yellowley, Professor Emeritus \\ Department of Mechanical Engineering, \\ University of British Columbia \\ yellowley@mech.ubc.ca
}

\begin{abstract}
Engineering design is the central process in the transformation of new ideas and conventional technology or practice into high value products and systems. Unfortunately the process is not highly valued within the research oriented University environment. At the same time government innovation policy is rooted in models better suited to the review of projects as opposed to systems or products; the value structure being biased towards discovery, (and perhaps use). The author attempts to describe the structure of typical design activities and using this model proposes simple metrics to allow the assessment of design content within research and development proposals.
\end{abstract}

\section{Introduction}

A much higher priority needs to be placed on design within our Universities. For this to happen there needs to be distinct funding available to encourage design directed activities (product and service creation) and there needs to be a change in culture within engineering faculties so that the "professional case" can be seen as equivalent (or better) than the current academic case for tenure and promotion. To make the case for such changes within a University system, (that has by and large neglected engineering design), is obviously difficult. A step change in a system with a time constant of 10-15 years will create severe disruption and one must make a very compelling case for the importance of design to engineering practice, the strategic value of design to national competitiveness and the intellectual challenges involved in the higher levels of the design process. To make a convincing case one must first define just what design includes and develop models to describe the process by which design creates value. Once one has a structure which describes the practice of engineering design and provides a model to demonstrate the potential to add value, one needs to add qualitative and quantitative measures to discriminate good design content. One presumes that the majority of design work within the University will not be assessed based on market performance (which in any case is dependent on many other factors).

A major difficulty in articulating modern engineering design ideas is the perception that design in the engineering context is limited to areas such as "Machine Design", (which unfortunately has little connection to real world design) and to "Industrial Design" which is believed by many to be "something one does at the end to make the product more acceptable or attractive to others"! The reality of course is that engineering design is the primary component in all the creative activities that engineers are involved in. It is apparent in it's purest and most powerful form at the highest levels of product and process or system design where product architecture is molded; specific design skills then continue down through the levels of the project, intertwined with both analysis and technology/practice based knowledge. Of the three areas which comprise the initial CDEN/RCCI view of Engineering, (Design, Analysis, Technology and Practice), the University environment has always stressed and rewarded analysis; the remaining two have attracted considerably less attention. The author believes that the lack of an exposure to typical practice over a wide range of areas is particularly worrying. Some schools have had the wisdom to introduce reverse engineering laboratories and of course there is ample room in early stage design courses (or indeed the engineering science stream) to add such exposure . The issue is the lack of motivation in many faculties to expose students to the vocabulary of engineering.

\section{Design}

There are several very different ideas as to what constitutes design. If we are thinking of a process which really adds value to engineering product and 
process development then many of the rather weak definitions quickly become inadequate. The following is a preliminary statement made by the author, [1], in response to the ame question asked by others, it is duplicated here for comment and discussion.

The simplest way to start the description is with a list. If the work contains all of these then it is certainly design.

a) A customer and an expression of requirements and preferences

b) The abstraction of customer needs (to allow greater creativity in their satisfaction)

c) The generation of broad conceptual solutions to the major requirements

d) A rudimentary engineering analysis and selection of preferred complete solutions

e) The detailed technical, economic, aesthetic and life cycle analysis of best alternatives,

f) The generation of documentation

g) Prototyping

h) Customer testing

i) Release to market

Given the breadth of engineering design then one needs to be careful to avoid a specific structure and the naming of specific methods. Also design is certainly not a linear process, one often needs to backtrack when major issues are revealed in preferred solutions. The real question is, "what items in the list above can be left out of an engineering design process and still have it reflect practice?" The answer will vary by discipline and by industry; for instance some companies find it more productive to understand the way customers think as opposed to asking them what they like. There will however almost always be elements that correspond to (a), (b) and (c) above. The major defining characteristics are,

a) The fact that the problem is not chosen to suit the tools available for analysis, but to attempt to satisfy a need or opportunity, (the tools must be found or developed and appropriate technology/practice researched)

b) The process of abstracting customer requirements to allow a broad range of concepts to be generated and compared

Often there may be very little detailed engineering analysis because of the nature of the product. There will always be a need to document what was done and some test of the design through prototyping; in some cases this may be through a physical model of the device or a software model where these are sufficient to ensure correct performance. Finally the need to examine the relevant economic, aesthetic, operational and life cycle issues are likely to be a core requirement

Table (1) Innovation policies

\begin{tabular}{|c|c|c|c|c|c|}
\hline & Innovation & Science & Research & Engineer/ing & Design \\
\hline Canada Policy1 & 1 & 0.25 & 0.66 & 0.03 & 0.015 \\
\hline Canada Policy 2 & 1 & 0.95 & 2.2 & 0.19 & 0.24 \\
\hline Hong Kong & 1 & 0 & 0.1 & 0.25 & 0.95 \\
\hline
\end{tabular}

Canada Policy Document 1:: Canada Achieving Excellence: investing in people, knowledge and opportunity. Canada Policy Document 2:: Knowledge Matters: Skills and learning for Canadians, http://www.innovationstrategy.gc.ca/

-Hong Kong: The Facts, Innovation.(Oct, 2004) Available from Hong Kong Innovation TechnologyCentre, http://www.itc.gov.hk/en/publications/press.htm 




Figure (1) The four quadrants proposed by Stokes [4]

of any design process. The operational requirements will vary according to the application but ease of use, maintainability, and safety are all likely to be major considerations. Design is now a large part of what the writer does and the contrast with what he has done in ((heavily) applied science is clear. For others the line between doing very good science that improves products and processes, with the process of actually designing these is blurred. The simplified description above is intended to try to contrast the differences. A design exercise forces one to first create, second analyze and third prove compliance.

\section{Assessment of Innovation}

The design community has not been particularly vocal or visible in making it's case with Government. Table (1) above shows the simple word counts in 3 different national documents on innovation; in each case the counts have been normalized on the word innovation, The predominance of research and science and almost complete lack of any awareness of design as the driving force behind innovation reflect a mentality still rooted in the linear models of innovation first postulated by Huxley [2] but more often attributed to Bush [3]. These linear models saw a simple progression from pure to applied research with product development as the final stage. The implication being that the value lay at the basic level of investigation and neglected any major consideration of the impact of integration and combination of technologies on the end value of the products or services delivered. More recent efforts to describe research and development have tended to take a more practical and thoughtful view. The work of Stokes, [4] is most well known and the basic premise is shown in Figure (1) where the total space is divided into 4 quadrants. The main point made by Stokes is that it is both possible and desirable to do work that is both basic and has application. Clearly this is the appropriate area to work in however one has to be careful in defining just what is new and what is actually useful! The approach is targeted towards the characterization of projects, this is very different to the characterization of product, processes or systems where the end result requires the integration of several

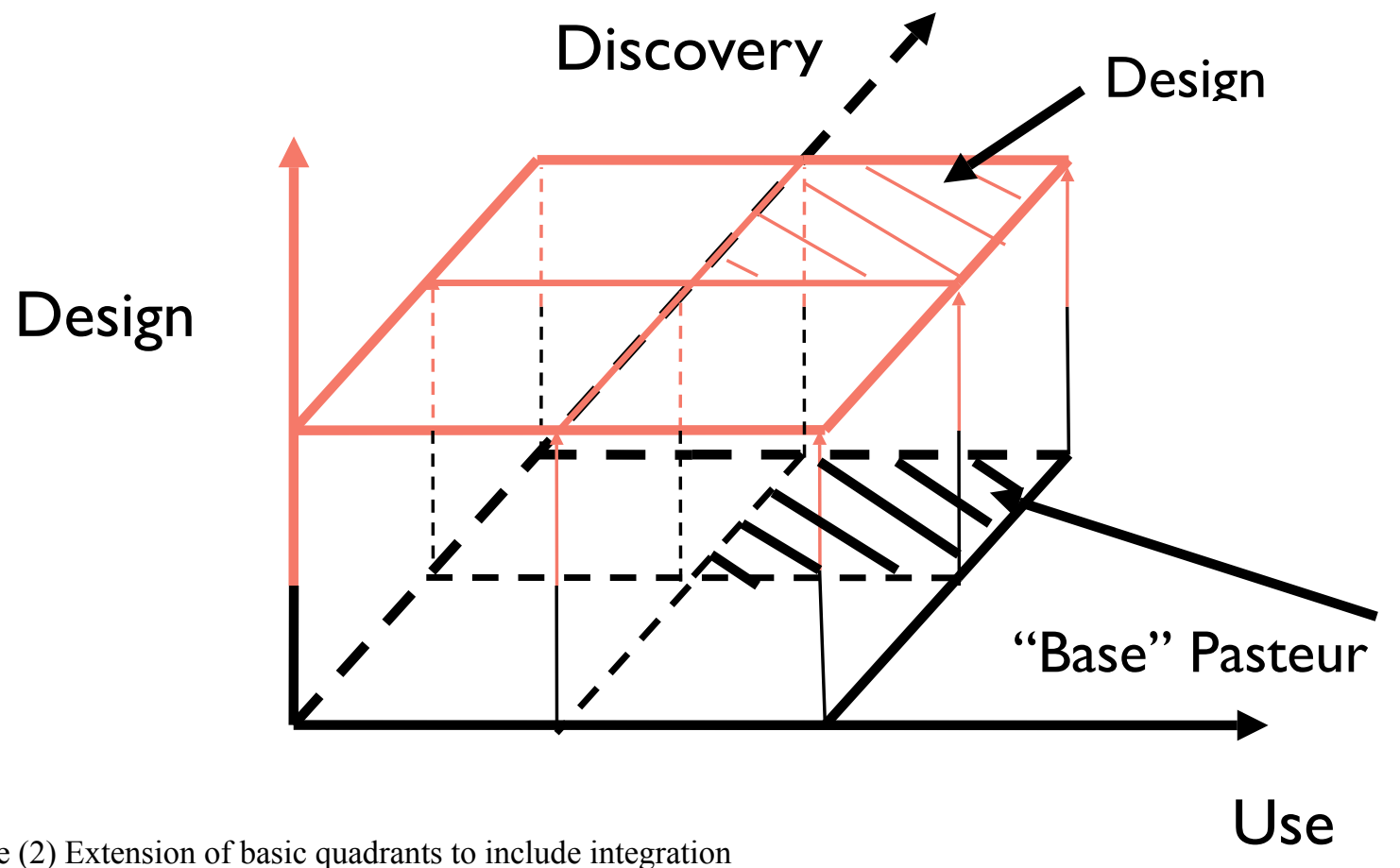

Figure (2) Extension of basic quadrants to include integration 


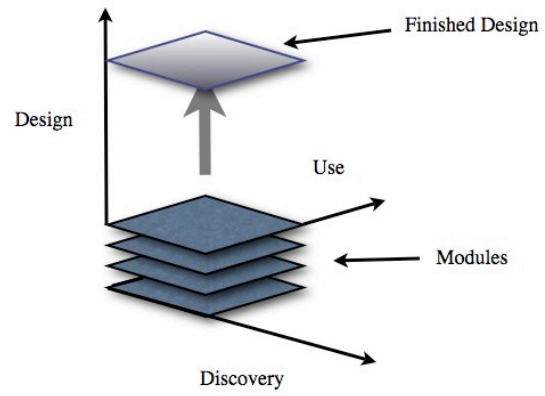

Figure (3) Adding value through design

such projects with existing technology and practice. It has been shown that this process (i.e. design) produces significant improvements in the value of the product. The method of combination being such that the value of the combination is considerably greater than the basic sum of the initial components. The latter becomes increasingly true in digital systems where multiple systems may be integrated in a single chip or module. The author has described such a situation in the design of CNC systems when the basic subsystems of motion, process and logic control are combined, (5). The added value is not simply due to the decrease in costs as a result of the combination, it comes in greater part from the possibility to perform new or improved functions as a result of the new possibilities for interaction and communication. One can also see cases where the introduction of a new material (e.g. carbon fibre), can be used to transform processes and form of products leading to the possibility of performance enhancements which are much greater than may have been expected. The important thing then is to examine the high level architectures and investigate the best approaches to the satisfaction of functionalities through the selection and integration of possible sub systems.

The approach described has been heavily researched and used in the design of complex products such as automobiles and computers, (Kodama, (6))

\section{Levels of Design Activity Within an Engineering Research Environment}

It is unlikely that the University community will move quickly towards a design driven research environment. there are hopes however that mechanisms could be put in place that encourage the integration of the design approach within research programs. This only makes sense where there is the potential for the development of products or processes that amplify the value being created in the research itself. It is likely that such activities will include external industry so as to add the market, history and technology awareness of particular markets that are unlikely to be well represented in the University.

The encouragement and funding of such activities is dependant on the community articulating the value proposition in a loud and uniform manner, it also depends upon a vision of just what might constitute a design contribution within such an environment. In examining the value of the design contribution one is really trying to estimate the potential value which may be added to the various pieces of new knowledge and the associated practice and technology. One must be realistic here, just adding design to the title of an activity does not add design content. The author has made a recent attempt to describe what is meant by design, and based on this, how one should categorize design contributions. These are included here for feedback and to act as a first approach. The list simply starts with one might regard as the first perceptible grain of design and continues through to the level one would like to achieve.

- a) The lowest level of design would be that which corresponds closely to the typical CAE approach and comprises the application of analysis to the improvement of cost, performance or efficiency. Typical examples would include minimum weight structures, process optimization etc

- b) The next level would include the optimization of performance or cost based on a series of complex constraints and also alternative design strategies. Typical applications to packaged (or modular) products or process planning etc

- c) This level is basically the standard design approach. It would include considerations of customer need and preference, concept generation and evaluation, consideration of economic, safety, ergonomic, lifecycle, manufacturing and strategic issues. Would normally see some abstraction and use of standard methodologies such as:: use cases, function structures, value engineering, (cost/worth 
analysis), morphological charts, QFD, FMEA, etc.. The base

- d) Level (c) plus new approaches to satisfying functionality are proposed.

- e) Level (c) or (d) with ambitions to create a completely new functionality

\section{Conclusions}

The author has described a very simple model of the design process that still captures the possibilities for the addition of value as a result of the design process itself. These ideas are useful in the process of developing methods of assessing projects with large design content, (as well as discovery and use components). It is the authors hope that such approaches will allow the design community to make a case for an increase in design activity within our faculties of engineering.

\section{References}

[1] I.Yellowley, JEDI Introduction, http:// www.cden.ca/JEDI/2006-April-editorial.html

[2] Huxley, J. S., Scientific research and social needs. London: Watts and Co., 1934

[3] Bush, V.. Science: The endless frontier.. Reprint, North Stratford, NH: Ayer Co., 1945

[4] D.E..Stokes, "Pasteur's Quadrant: Basic Science and technological Innovation, Brookings Institution Press, 1997

[5] I.Yellowley, Design directed research and Education, http://www.cden.ca/lecturers.htm

[6] F. Kodama "Technology Fusion and The new R\&D”, Harvard Business Revue, pp 70-78, JulyAugust, 1992 
